\title{
PROPOSTAS FORMADORAS DA IGREJA BATISTA PARA A SOCIEDADE: DEMOCRACIA E FAMÍLIA (MINAS GERAIS, DÉCADA DE 1920)
}

\author{
Taciana Brasil dos Santos \\ Universidade Federal de Minas Gerais (UFMG)
}

\begin{abstract}
RESUMO
O texto pretende identificar como o periódico O Baptista Mineiro e o Collegio Baptista Americano Mineiro cooperaram enquanto estratégias de difusão dos princípios da Igreja Batista para a vida em sociedade, durante a década de 1920. Para tal, serão analisados materiais impressos, como o próprio periódico, além de materiais referentes ao Collegio, como prospectos de propaganda, Archivo de Notas Finaes e livros comemorativos da instituição. Como limites à identificação dos princípios para a sociedade, partiremos do ideal democrático e das representações de família contidas nas fontes.

Palavras-chave: sociedade; escola; imprensa; democracia; família; Igreja Batista.

\section{PROPOSALS FORMING THE BAPTIST CHURCH TO SOCIETY: FAMILY AND DEMOCRACY (MINAS GERAIS, 1920s)}

\begin{abstract}
The text aims to identify as the periodical The $O$ Baptista Mineiro and Collegio Baptista Americano Mineiro cooperated as a strategy for disseminating principles of the Baptist Church for life in society during the 1920s. This will be examined printed materials, as the journal, and related materials Collegio, as prospects for advertising, Archivo de Notas Finaes and books commemorating the institution. As limits the identification of principles for the society, part of the democratic ideal and family representations contained in the sources.
\end{abstract}

Keywords: society; school; media; democracy; family; Baptist Church.

\section{Introdução}

Em Minas Gerais, historicamente, a Igreja Católica tem marcante presença na constituição dos valores morais e religiosos da sociedade. Conforme Passos (2002, p. 185), "o catolicismo produzia o cidadão".

Se tomarmos como exemplo o contexto escolar no início do século XX, podemos observar forte influência das doutrinas e princípios católicos. Embora o decreto de João Pinheiro, em 1906, suprimisse o ensino religioso das escolas públicas, ainda assim a escola era um dos principais alvos da campanha para a recristianização da sociedade mineira (Peixoto, 1993, p. 58) promovida pelo clero, com o objetivo de manter a hegemonia da Igreja neste Estado. Conforme Souza (2006), "formar o cidadão, a partir das escolas públicas da capital mineira, constituía, com grande ênfase, em formá-lo a partir da doutrina religiosa católica" (p. 13).

Mas não era apenas a Igreja Católica que pretendia implantar seus valores na sociedade. Durante esse mesmo período, crescia em Belo Horizonte, um novo movimento religioso: a Igreja Batista. E os batistas também trouxeram consigo princípios, tanto pessoais quanto para aplicação em toda a sociedade brasileira. 
Desde 1896 já havia batistas em Belo Horizonte, porém nenhum dos missionários americanos se estabeleceu definitivamente nesta cidade. Apenas em 1911 o missionário Daniel F. Crosland é enviado definitivamente para a capital mineira, onde encontra um pequeno grupo de dez fiéis, com os quais trabalha para alcançar toda a capital. Mesquita (1940), ao escrever a História dos Batistas do Brasil, relata que uma das principais dificuldades encontradas por Crosland foi o tamanho do estado mineiro e o grande número de municípios. Não havia trabalhadores suficientes para difundir a mensagem batista por todo o território.

Em dezembro de 1917, foi enviada para Belo Horizonte a família Maddox, que já trabalhava pela causa batista por anos a fio no Rio de Janeiro. Assim que a família Maddox chegou a Minas, o trabalho batista tomou novo ânimo, organizando-se, já em 1918, a Escola Baptista de Bello Horizonte, transformada a partir de 1920 em Collegio Baptista Americano Mineiro. Apenas dois anos depois, em 1920, iniciava-se a publicação do periódico $O$ Baptista Mineiro, em circulação até a presente data. Como podemos observar, ambas as iniciativas permaneceram até os dias de hoje - o que pode comprovar que atenderam de forma eficaz os ideais dos batistas para essas instituições ao longo de todo esse tempo. E quais seriam esses ideais?

O interesse dos batistas pela implantação de uma escola justificou-se pelos mesmos através da necessidade de uma instituição que proporcionasse o melhor desenvolvimento de seus filhos (50 anos, 1968). Segundo a Ata de Fundação da Escola, almejava-se com a criação da instituição alcançar ...o preparo conveniente dos nossos filhos para servirem (...) em qualquer esphera mormente na Causa de Jesús (O Colégio Baptista Mineiro, $40^{\circ}$ Aniversário, 1958, p. 5). As razões apontadas para sua criação são o ultimo abuso commettido nas Escolas Publicas com a collocação dos crucifixos nos edifícios e tambem a deficiencia no ensino secular das mesmas Escolas (idem).

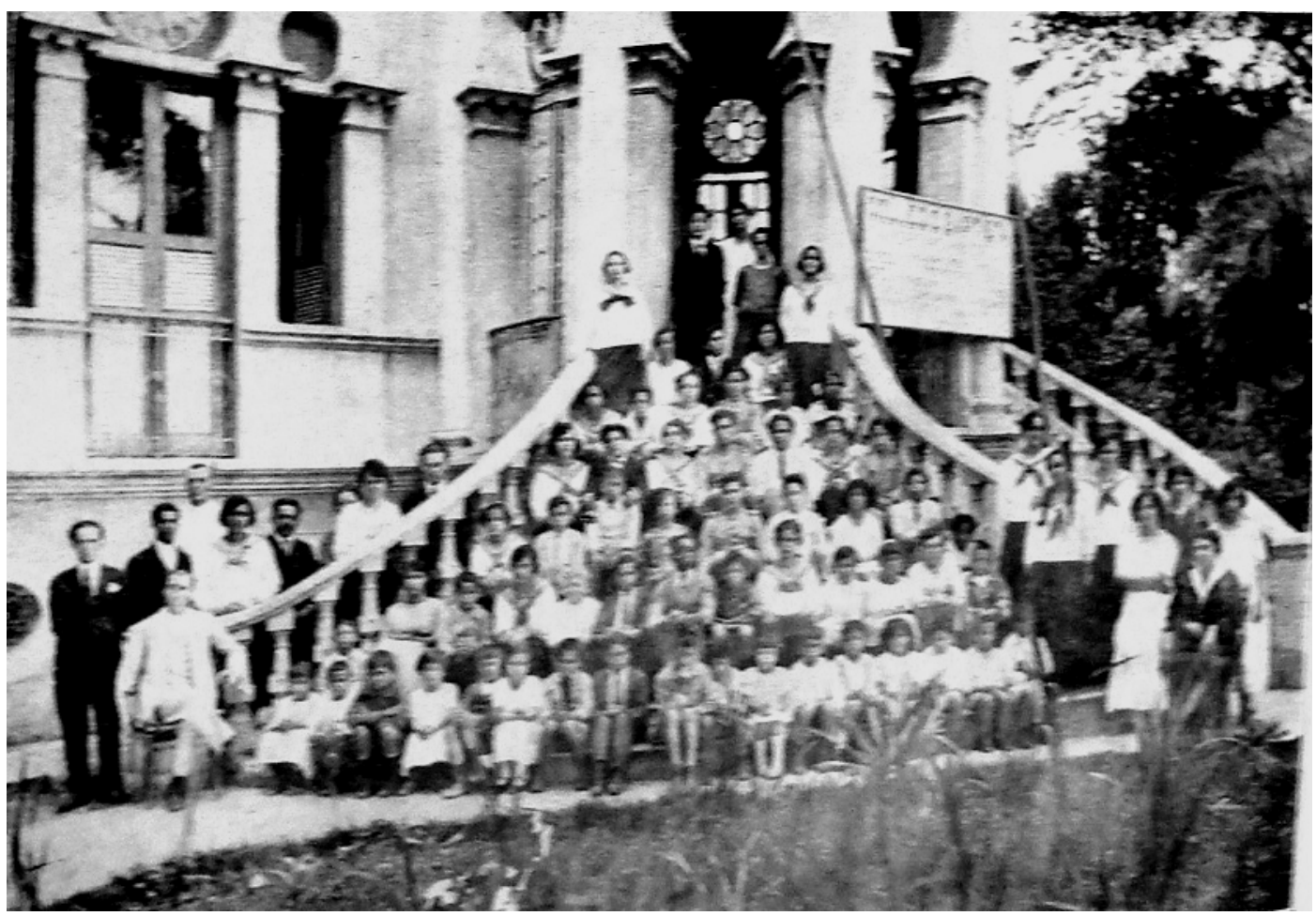

Figura 1 - Alunos do Collegio Baptista Americano Mineiro na escadaria do Palacete Sabino Barroso, que funcionava como prédio de aulas $(1927$, s.p.) 
O Baptista Mineiro seria enviado mensalmente a todos os lares batistas mineiros. Quanto à utilidade de um periódico batista, o missionário Henrique E. Cockell escreveu:

...uma cousa indispensavel para o feliz exito da Causa de Jesus neste Campo, como o é em todos os Campos, pois que nenhuma causa pode attingir o seu alvo sem que tenha um meio de informar, colligar e unificar os seus defensores e o jornal é o que melhor a isso se presta;... (O Baptista Mineiro, n. 1, jan/1920, p. 1)

Conforme pudemos observar, segundo as palavras de Cockell, pretendia-se que $O$ Baptista Mineiro fosse um veículo formador e informador dos batistas no estado. Considerando-se a facilidade de difusão do texto escrito, podemos concluir que, em parte, estava solucionado o problema com o pequeno número de ministros religiosos para atender toda a população. Não seria necessária a presença física de um ministro para a transmissão desses princípios; o veículo impresso substituiria sua ausência temporária.

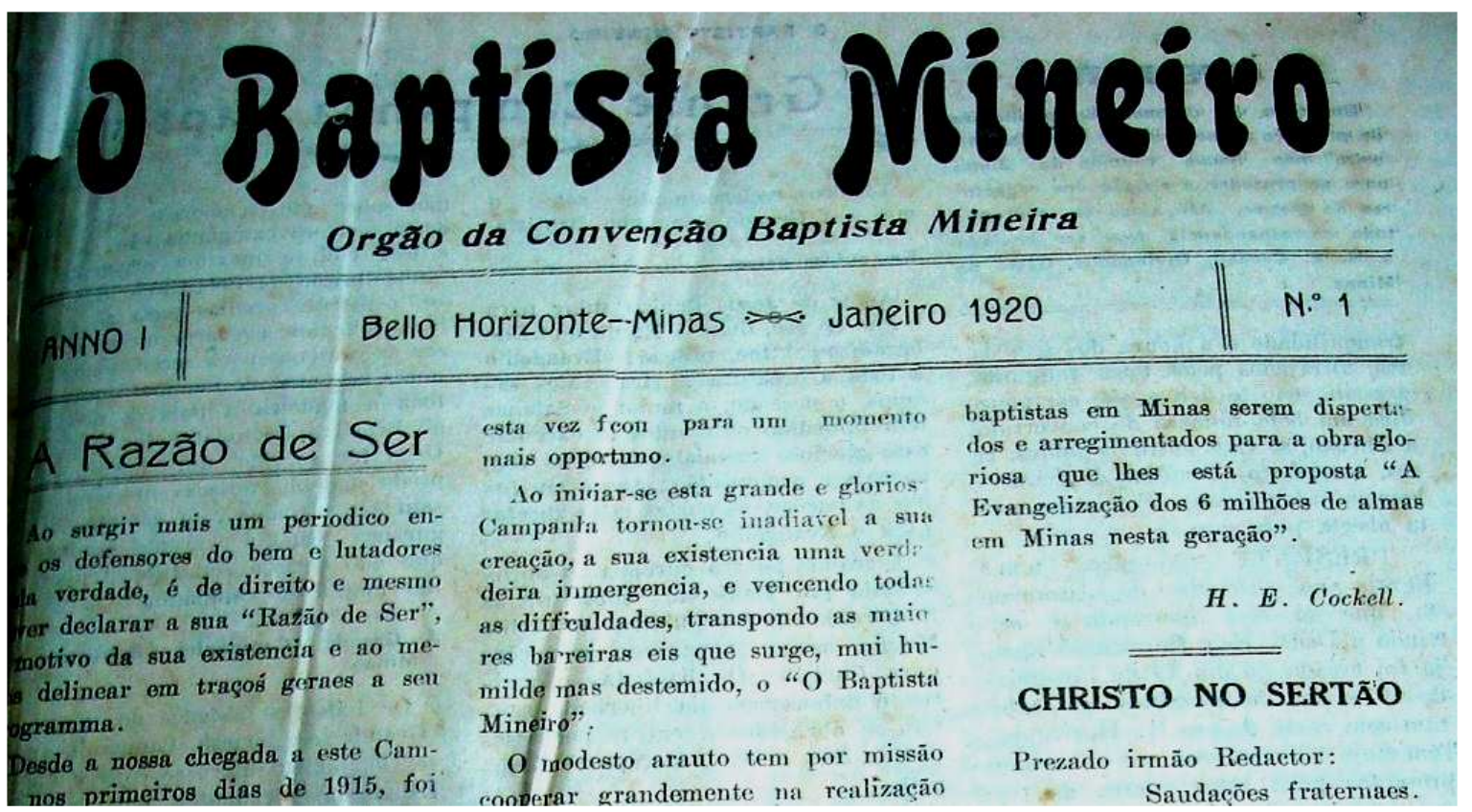

Figura 2 - Cabeçalho do primeiro número de $O$ Baptista Mineiro, janeiro de 1920.

Assim, o Collegio Baptista Americano Mineiro e $O$ Baptista Mineiro podem ser considerados dois dos principais veículos transmissores e inculcadores dos princípios batistas no estado. Enquanto o Collegio inculcava a nova geração, o periódico alcançava os mais velhos. A principal forma de transmissão da doutrina batista seria a educação, e sua principal entrada seria a família. Assim, toda a sociedade poderia ser influenciada pelos princípios da denominação.

Buscar-se-á, portanto, nesse trabalho, identificar parte do ideal de sociedade que os batistas almejavam alcançar difundindo seus princípios. Devido à predileção dos primeiros líderes batistas em alcançar a sociedade através da família, buscar-se-á ainda delimitar as representações de família contidas nos dois principais veículos difusores da doutrina batista em Minas Gerais. Esclareço, porém, que ao citar os "princípios centrais da doutrina batista", não me refiro aos princípios teológicos, e sim aos princípios de comportamento e estilo de vida idealizados nas fontes consultadas. Na pesquisa, serão utilizados exemplares de $O$ Baptista Mineiro, bem como prospectos de propaganda do Collegio e o Archivo de 
Notas Finaes, durante a década de 1920 - período de grande investimento por parte da denominação, por se tratar da expansão inicial de seu trabalho no estado. Serão consultados também livros comemorativos do Collegio Baptista Americano Mineiro, e suas referências ao mesmo recorte temporal.

\title{
$O$ ideal de sociedade democrática
}

As igrejas batistas, em geral, são governadas democraticamente. Qualquer questão é decidida em assembleia, através da exposição de argumentações e voto dos membros. $\mathrm{O}$ artigo O que é uma Egreja Baptista, de Maio de 1920, ressalta essas características:

3. É um corpo egual em ordem e privilegios. Classes governadoras são estranhas á egreja evangelica, ou aos Evangelhos.

4. É um corpo que dirige os seus negócios sob a leaderança de Jesus. Isto quer dizer que a egreja baptista local governa-se a si mesma e não tem outro chefe além de Jesus Christo. A forma de governo é congregacional e democratica e tem em si todo o poder administractivo e judiciario que necessita. (O Baptista Mineiro, maio/1920, p. 2)

No momento de implantação em Minas, o interesse dos batistas pela democracia ia além do eclesiástico, perpassando a participação ativa na sociedade. Os batistas almejavam a implantação da democracia da mesma forma que almejavam a implantação de suas doutrinas religiosas. Para isso, seus veículos formadores trabalhavam ativamente.

Já no primeiro número de O Baptista Mineiro, podemos perceber o compromisso da causa batista com a implantação e o exercício da democracia a nível mundial. Na página 2, Ottis P. Maddox escreve, em seu artigo "A Grande Campanha Baptista", sobre o assunto:

\begin{abstract}
A grande guerra européa foi aproveitada por Deus em substituir as monarchias por republicas no Velho Mundo, assim preparando as nações para Christo. Os baptistas, pioneiros e defensores da liberdade sentem-se obrigados a entrar por essas portas com a luz benefica do Evangelho. (...) Os povos estão á espera da mensagem baptista. Quem lhes ha de negal-a? (O Baptista Mineiro, jan/1920, p. 2)
\end{abstract}

Conforme podemos observar, Maddox, que é um dos principais nomes da causa batista em Minas, acredita que a implantação da democracia não só abria as portas para que a mensagem batista entrasse nos países, como criava, aos batistas, a obrigação de levá-la até lá.

Ainda no mesmo exemplar, no artigo "A Campanha e a Educação", Achilles Barbosa demonstra o nível de compromisso com o ideal democrático que se esperava do batista, sobretudo do mineiro:

Conhecendo a psychologia do povo mineiro pelo compulso da sua historia, pelo convívio com elle e por sentir pulsar no peito um coração de mineiro, sei que os princípios baptistas, de liberdade e democracia, hão ... vingar exauberantemente em nosso meio, porque existe o gérmen latente delles em todas as consciencias dos que viram a luz da vida nestas Alterosas. O mineiro é livre por índole e democrata de coração. O primeiro sangue derramado, no Brasil, em prol da liberdade foi o mineiro. 
Daqui veremos, não em época muito remota, sahir os campeões baptistas, com o sacrificio do proprio sangue si fôr mister, para implantar os principios de liberdade e democracia no Brasil e no mundo. (idem, p. 3)

Barbosa mescla a difusão da democracia e dos princípios batistas. O compromisso com a pátria era tão fundamental quanto o compromisso com a doutrina batista. Percebemos este ideal também na educação das crianças. $\mathrm{O}$ desejo dos batistas era que, desde cedo, elas fossem treinadas para participar ativamente de uma sociedade democrática. Assim, o Collegio Baptista Americano Mineiro realizava atividades com o objetivo de desenvolver nos alunos as competências necessárias a essa tarefa. Entre estas atividades, destaca-se o Club Litterario, conforme veremos a seguir:

Uma das cousas mais difficeis de conquistar é a arte de falar bem.

Para attingir o desenvolvimento intellectual e rethorico dos alumnos, o Collegio organizou um Club Litterario, a que chamamos "Tiradentes", em homenagem ao magnânimo heroe mineiro.

Todos os alumnos são obrigados a ser sócios deste club e tomar parte nos seus programmas. (Prospecto 1927, p. 9-10)

Veja também:

É claro que nossos estudantes têm de tomar parte activa na vida social, política e religiosa deste Estado e nação. Afim de cultivarmos os habitos de pensar e falar em publico, sem timidez, sem temor e sem atrapalhação alguma organizamos este club literario. Todos os discipulos assistiram estas reuniões. Agora nossos programmas são realizados de duas em duas semanas, dando programmas extraordinários nos dias de festas nacionaes. Os effeitos deste trabalho são patentes. (Relatorio do Collegio Baptista Americano-Mineiro á Convenção Baptista de Minas Geraes em 1921, in O Baptista Mineiro, set./1921, p.3)

Em 50 anos (1968, p. 26) encontramos ainda: Dias especiais eram marcados e destacados alunos para sustentarem debates sôbre vários assuntos, cuja vitória era determinada pelo julgamento e votação da maioria. Até mesmo o nome do Club Litterario evoca a democracia, trazendo à memória a Inconfidência Mineira. As atividades especiais realizadas nos dias de festas nacionais evocavam o caráter patriótico da formação oferecida. $\mathrm{O}$ desenvolvimento da capacidade retórica das crianças parece ter por objetivo principal torná-las aptas a expor e defender suas ideias perante o público, e essa exposição culminava em uma votação. Com esse treinamento, as crianças saberiam se portar bem em uma situação de eleição: além de estarem treinadas a ouvir discursos e escolher qual lhes parece melhor, estavam também treinadas a fazer os discursos, caso assim desejassem.

Resta um questionamento: se as atividades realizadas no Club Litterario eram obrigatórias, como essas crianças poderiam estar sendo treinadas para viver em uma sociedade democrática? Não deveria ser confiado a elas o direito de escolha entre participar ou não de uma atividade que não faz parte do currículo escolar? Para chegar a uma conclusão a esse respeito, passarei à análise de uma outra atividade cotidiana do Collegio, e que também não fazia parte do currículo escolar: o Ensino Religioso.

O Collegio foi concebido para educar os filhos dos batistas, conforme seus princípios. E a formação religiosa não se afastava desse intuito, conforme já foi dito na Introdução. Ainda assim, aceitavam-se alunos oriundos de famílias não-batistas. Se consultarmos os Archivos de Notas Finaes, poderemos verificar que as confissões 
religiosas das famílias que matriculavam seus filhos na escola era bastante variada. Todas estas deveriam estar cientes de que o intento era construir uma escola confessional batista, e que valores batistas seriam transmitidos em sala de aula. Segundo o ítem Ensino Religioso dos prospectos de 1924 e 1927, não era necessário que os alunos se tornassem batistas, apenas que participassem passivamente dos cultos no início das aulas. Ficaria a cargo dos próprios alunos seguir ou não aos princípios religiosos ensinados no culto. Nesse caso, eles teriam a liberdade de escolha limitada às práticas religiosas pessoais. Ainda assim, deveriam ouvir diariamente os argumentos batistas. Seria, de fato, possível exercer a liberdade de escolha nesta situação? Ou o Colégio seria uma "fábrica de militantes batistas"?

Recorro, então, a uma relação de ex-alunos considerados ativos na militância batista contida na publicação $40^{\circ}$ Aniversário:

Depois da mudança do Colégio para a Rua Pouso Alegre êle incluiu entre outros, no seu rol os seguintes alunos: Munelar, Álvaro e Irema Maia, Maria de Oliveira (Malheiros), Iracema Silva (Gatti) Artemia de Paoli, (Rodrigues), Mozart Faria, Antônio Silveira, Hélio Brasil, Astrogildo Malheiros e outros que são ativos no trabalho Batista. (1958, s.p.)

Ao consultar no Archivo de Notas Finaes os nomes desses alunos, pode-se verificar que apenas Mozart Faria não é designado como oriundo de família batista - o que não exclui essa possibilidade, visto que o campo "Religião" em seus dados pessoais não foi preenchido.

Embora a possibilidade de escolha existisse, a obrigatoriedade de presença nos cultos religiosos pode ter sido o suficiente para inculcar em muitos alunos de famílias nãobatistas os princípios religiosos dos fundadores do Collegio. Mesmo porque, segundo Peixoto (2003, p.28), "mediante comportamentos aprendidos coletivamente na escola, os indivíduos reproduzem formas individuais de comportamento coletivo". Assim, podemos entender que a simples assistência dos cultos matutinos pode ter influenciado vários comportamentos individuais.

Após a análise da forma como os alunos participavam das atividades propostas pela instituição, conclui-se que o intuito era preparar as crianças para serem ativos cidadãos em uma sociedade democrática. A participação na sociedade, no entanto, era considerada uma obrigação da qual não se pode omitir. Por isso, as crianças eram obrigadas a tomar parte nas atividades formadoras do espírito democrático. Mas quanto à prática religiosa, o direito de escolha dos alunos só seria ativamente exercido em momentos em que não estivessem sob a autoridade escolar: seja porque estão em momento de prática religiosa junto às suas famílias, seja porque se tornaram adultos e podem exercer a liberdade na democrática sociedade brasileira. Em ambos os casos, cabe lembrar que seus comportamentos certamente foram influenciados por sua permanência no Collegio. Este pensamento pode ser confirmado por meio do artigo A Educação Christã, de O Baptista Mineiro, de dezembro de 1926:

A verdadeira educação prepara o individuo para o gozo integral de todos os seus direitos e para o fiel cumprimento de todos os seus deveres para com o proximo e para com Deus. Ella abrange o cultivo de todas as faculdades do homem, equilibra-lhe as actividades e prepara-o para estabelecer as melhores relações, sociaes e religiosas. (O Baptista Mineiro, dez./1926, p. 2) 


\section{Representações de família}

Os batistas optaram pela família como principal porta de entrada para sua mensagem. Conforme foi dito anteriormente, O Baptista Mineiro foi concebido para alcançar os mais velhos, enquanto o Collegio Baptista Americano Mineiro foi concebido para alcançar a geração mais jovem. Desta forma, toda a família seria alcançada.

A divulgação da mensagem batista através do periódico, porém, poderia não surtir efeito quanto a alcançar novos fiéis. Sua distribuição era feita apenas em lares batistas; o que o tornaria útil apenas à consolidação e formação dos fiéis conquistados. Mas observe o que foi escrito acerca dos objetivos do periódico logo no primeiro exemplar impresso, no artigo A razão de ser:

Visitará mensalmente cada lar baptista mineiro afim de ensinar, inspirar, animar, aconselhar, etc. e desta sorte ajudar a todos a attingirem "o alvo da soberana vocação".

Feliz momento quando fomos impellidos á creação de nosso jornalzinho, pois, só assim poderão os 700 baptistas em Minas serem dispertados e arregimentados para a obra gloriosa que lhes está proposta "A Evangelização dos 6 milhões de almas em Minas nesta geração". (O Baptista Mineiro, jan./1920, p. 1 Aspas originais.)

Embora não fosse distribuido em lares não-batistas, o periódico tinha por objetivo incitar cada família batista a levar pessoalmente a mensagem de sua Igreja a outras famílias de sua comunidade. No artigo Sobre o erro, maldade!, de agosto de 1921, relata-se o exemplo de um homem batista que residia no interior: "A quatro horas de viagem de Bello Horizonte (...) na cidade de Itauna, havia um velho baptista, veneravel ancião, por todos acatado e que accesso tinha aos lares mais catholicos." (O Baptista Mineiro, ago./1921, p. 1). A divulgação da mensagem e da causa batista, portanto, se daria também pessoalmente, de família a família.

E não eram apenas as famílias leitoras d'O Baptista Mineiro que tinham essa obrigação. Os missionários norte-americanos também trabalhavam dessa mesma forma em suas incursões no interior mineiro, conforme veremos a seguir:

No sabbado, 10, atravessámos o rio São João em demanda de um logar denominado Carneiro e passámos a noite em casa do Sr. Miguel Viégas, que nos recebeu de boamente. A este Sr. e familia tivemos occasião de dar algumas explicações sobre a Salvação por meio de Jesus Nosso Senhor. (...) resolvemos seguir a viagem a pé, pois tinhamos compromisso de estar no pequeno povoado por nome Casquilho, am meio-dia, para alli realizarmos um culto. A distancia a ser vencida era de legua e meia a duas leguas, mas, gastámos cinco horas em caminho e isto não porque andássemos de vagar, mas, porque fomos passando de casa em casa pelos sitios e annunciando o Evangelho de Salvação ás pessoas naquella zona. Chegados ao nosso destino, casa do Sr. Alfredo Reis, onde deviamos realizar o culto, (...) dando margem para uma longa conversa e muitas explicações ao Sr. Antonio Reis, bem como aos amigos que estavam se reunindo. (O Baptista Mineiro, abr./1920, p.4.)

As famílias e suas redes de sociabilidades eram o principal alvo dos missionários. As viagens eram planejadas para possibilitar seu alcance. Seja nas reuniões previamente 
marcadas, seja nas visitas casa a casa em comunidades, o alvo nunca era o indivíduo, e sim a família como um corpo integrado.

Para os batistas, portanto, a família era a unidade básica de recepção da mensagem batista. Não apenas de recepção, mas também de divulgação. Se observarmos a organização do trabalho dos missionários, veremos que suas esposas tinham ativa participação no mesmo. Vejamos o exemplo do Collegio no prospecto para o ano de 1927 (1927, s.p.): O Collegio Baptista Americano Mineiro abriu-se no dia $1^{\circ}$ de Março de 1918, como uma escola annexa em casa do missionário Dr. O. P. Maddox, em Bello Horizonte, sob a direção de Mrs, O. P. Maddox. Documentos acerca da fundação da instituição apresentam o Dr. Maddox como seu principal idealizador. Após a fundação, sua esposa tornou-se a principal responsável pelo trabalho durante vários anos. Com o crescimento da instituição, aumentaram os cargos. Porém a presença de elos familiares ainda era fortemente percebida, conforme o exemplo abaixo:

O internato feminino é a bonita e espaçosa casa $n^{\circ} 911$ - rua Pouso Alegre, chamada "Chacara Negrão". Não há uma casa nesta cidade mais bem situada do que aquella. É bem retirada da rua e as moças podem alli viver socegadamente. O Deão do collegio reside alli com sua família, e toma conta das moças. $(1924, s . p$.

As famílias confiariam suas moças não apenas ao cuidado do Collegio através da pessoa do deão, mas também de sua família, considerada parte integrante de sua missão. Nesse mesmo prospecto, há uma relação de nomes de funcionários da instituição, em que se percebe a presença de alguns casais: F.A.R. Morgan, Director, e Gertrudes Morgan, superintendente do Curso Normal; e J.R. Allen e Margie Allen, superintendentes do internato feminino. No caso da já citada família Maddox, a mãe, Ephigenia Maddox, durante o ano de 1924, lecionou Psychologia e Hygiene, enquanto que seu filho, Paul Maddox, era Director de Gymnastica. Sem contar que os filhos de muitos dos funcionários lá estudavam, aumentando o ambiente de proximidade familiar dentro da instituição. De fato, manter um ambiente familiar era objetivo do Collegio: Relações familiares são mantidas com os alumnos da melhor forma possível. A disciplina é enérgica, porém paternal, com o intuito de desenvolver a ordem na vida educativa do alumno. (1927, s.p.) Dessa forma, a família - ou o ambiente familiar - também se faz presente enquanto estratégia $^{1}$ transmissora e receptora da mensagem batista, já que se mantinham relações familiares com os alunos.

Qual a razão da predileção dos batistas pela família e ambiente familiar para a divulgação de sua mensagem? Encontramos pistas da resposta para essa pergunta no artigo Meditações sobre Educação, de 1928:

O CARACTER do nosso systema de educação ha de determinar o caracter do nosso povo e isto dentro de cincoenta annos. Qual ha de ser o futuro do povo baptista? A resposta depende de desempenharmos o papel de educarmos bem os nossos filhos. (...) (O Baptista Mineiro, nov. dez./1928, p. 1 - realce original)

A família é o principal ambiente socializador da nova geração. Os principais comportamentos sociais são aprendidos nesse ambiente. Se esse ambiente estiver impregnado da doutrina batista, a nova geração terá sido eficazmente alcançada. O dever

\footnotetext{
${ }^{1} \mathrm{O}$ conceito de estratégia, neste texto, advém do campo historiográfico, cf. Certeau (1998).
} 
dos mais velhos era educar os mais jovens para esse fim, conforme veremos no trecho do já citado A Campanha e a Educação, de 1920:

O êxito dessa campanha decidirá da sorte da nossa educação e a denominação só escapará ao naufragio si elevarmos aquella á altura do nosso ideal. (...)

...quem fugir ao dever constitue-se traidor; nesta hora decisiva os neutros são inimigos, deixar de ser lutador é ser vencido, não vibrar a lança pelo Evangelho é deixar a causa das trevas triumphar!

Appellam para nós os nossos filhos, aos nossos sentimentos de paes e de christãos; deixal-os sem instrucção é fazel-os inuteis; dar-lhes uma instrucção defeituosa é fazel-os prejudiciaes. Da agrura desse dilemma cruel fugiremos cumprindo o nosso dever para com a campanha, alistando-nos nella para defendel-a e levar avante os seus nobres e grandiosos objectivos. (O Baptista Mineiro, jan./1920, p. 4)

Deixar de educar os filhos de acordo com os princípios batistas é considerado pelo escritor uma traição à causa. Traição esta que traria consigo a condenação daqueles que não receberam a educação adequada à categoria de "prejudiciaes".

Como seria a educação adequada, de acordo com os batistas? O artigo A Educação Christã, de 1926, a descreve:

...Uma boa educação é o melhor thesouro que se pode dar a um filho, porque nem este o desperdiça nem os ladrões lh'o podem roubar. (...)

Onde poderão os nossos filhos adquirir uma boa educação? No lar christão, na escola christã e na egreja christã. Em qualquer destes meios, o lar, a escola e a egreja, é indispensavel o predominio do Evangelho, pois é o único poder capaz de salvar e educar christãmente o individuo.

Temos nós um collegio evangelico na altura de dar solida instrucção e optima educação christã? Um collegio que complete a educação do lar e ponha o alumno ao contacto do Evangelho? Graças a Deus, o Collegio Baptista Americano Mineiro, fundado no coração de Minas, está em condições invejaveis de satisfazer esse elevado ideal dos paes intelligentes, que procuram educar os filhos para uma vida feliz e serviçal. (O Baptista Mineiro, dez./1926, p. 2)

As três estratégias reconhecidas como formadoras da nova geração são "o lar, a escola e a egreja". Não há uma confiança absoluta acerca da capacidade da família em educar corretamente essas crianças sem o auxílio de outras estratégias propriamente batistas.

Quando uma família matriculava seus filhos no Collegio Baptista Americano Mineiro, submetia-os a sua autoridade e disciplina. Para exercê-las adequadamente, a instituição contava com o apoio por parte das famílias, conforme o seguinte trecho da Ata de Fundação:

Pastor H. E. Cockell fallou sobre "Os Deveres e as opportunidades dos paes para com a Escola" no decorrer do que disse assentuou cinco pontos essenciaes, dizendo: "Zelar pela pontualidade dos alumnos". "Cuidar do asseio dos mesmos - corpo - roupa - linguagem". "Ver que preparam as lições marcadas para casa". "Apoio moral á Escola - diretora e professores". "Orar constantemente em favor da Escola". (O Colégio Batista Mineiro: $40^{\circ}$ Aniversário, p. 5 Aspas originais.) 
Apesar de a instituição representar-se como estratégia disciplinar sobre a vida do aluno e, até certo ponto, sobre a vida da família - que passa a ter obrigações específicas, indicadas pela instituição -, ela representa a família como força capaz de impulsionar ou dificultar seu projeto. Outro exemplo disso é encontrado no Prospecto de 1924: Em todos os demais casos de disciplina, a secretaria communicar-se-á com os paes, afim de cooperarem no sentido de que o alumno se corrija antes da elliminação (1924, s.p.). Ou seja, embora a instituição faça aquilo que está a seu alcance para educar a nova geração, quando seus esforços falham, a família é quem ainda pode fazer alguma coisa. A Escola considerava, também, que a formação disciplinar que oferecia beneficiava a própria família: "Para o bem dos paes, dos alumnos e da instituição, a disciplina precisa ser rigorosa afim de desenvolver o devido respeito." (1924, s.p.). Assim, a família é representada como necessitada da interferência da estratégia batista até mesmo para manter sua harmonia.

Em certas situações, a família é representada como passível de não buscar o bem da criança com a mesma responsabilidade que o Collegio. Assim, até mesmo os pais lhe deveriam explicações em alguns casos: ...A ausência terá de ser justificada perante o director, mediante uma explicação escripta pelos paes. É de summa importância que os paes não sanccionem desculpas, a não ser que sejam bem justificadas (1924, s.p.). Assim, o Collegio representa-se como guardiã do direito e dever dos alunos de aprender, ao passo que representa a família como passível de criar situações para que a criança não usufrua de sua condição de aprendizado.

Mesmo nos momentos de folga dos alunos, a autoridade escolar se apresenta em paridade - ou até mesmo superioridade - com a autoridade familiar, conforme podemos ver nos exemplos abaixo:

Os alumnos internos poderão sahir aos sabbados, desde que sejam acompanhados por seus paes ou pessoas por elles encarregadas, mediante o consentimento expresso do director. O número de vezes, porém, de sahidas será limitado a uma vez por mez, podendo o alumno gozar maior numero de vezes de sahidas, desde que tenha bom procedimento e medias optimas. Também receberão visitas autorizadas pelos paes durante o

E: período de recreio. (1927, s.p.)

$2^{\circ}$ - Não é permitido passar o domingo fora do internato senão em casa dos paes ou parentes, e isto sómente em casos excepcionaes e com o consentimento do director. Para passar a noite fora do internato é preciso ter o consentimento dos paes por escripto e também do director. O gozo de qualquer desses privilégios dependerá da seriedade e bom procedimento do alumno. (1927, s.p.)

Não bastava o consentimento familiar; era necessário também o consentimento do diretor.

O rendimento escolar também manifesta esse princípio. A família era informada através de boletins, e deveria manifestar ao diretor sua ciência acerca da situação escolar da criança:

Boletins mensaes são enviados aos paes mostrando as notas nas matérias, a applicação, comportamento e freqüência do alumno. Taes boletins devem ser assignados pelos Paes e devolvidos ao director da instituição. 
Assim, os Paes podem desde logo apreciar o estimulo que advem de tal systema. (1924, s.p.)

Conclui-se destas observações que a família, para os batistas, era o elo que possibilitaria alcançar toda a sociedade. As redes de sociabilidade entre famílias permitiriam a divulgação da mensagem à presente geração. A presença dos princípios batistas dentro da família garantiria a formação das futuras gerações do grupo religioso. $\mathrm{E}$ mesmo quando a família falhasse em transmitir esses princípios, as outras estratégias educacionais batistas - o Collegio e a Igreja - complementariam a educação familiar, através da presença de valores e mesmo modelos de convivência familiar que deveriam ser seguidos pelas crianças.

\section{Referências}

Fontes impressas e mimeografadas (Acervo do Centro de Memória do Colégio Batista Mineiro)

Archivo de Notas Finaes do Collegio Baptista Americano Mineiro.

Collegio Baptista Americano Mineiro. Belo Horizonte. 1921.

Collegio Baptista Americano Mineiro. Belo Horizonte. 1924.

Collegio Baptista Americano Mineiro. Belo Horizonte. 1927.

O COLÉGIO BATISTA MINEIRO. 40 Aniversário. Belo Horizonte. 1958.

50 ANOS: 1918-1968. Belo Horizonte. 1968.

A educação christã. O Baptista Mineiro, anno VII, n. 12, p. 2, dez. 1926.

A.B. Sobre o erro, maldade! O Baptista Mineiro, anno II, n. 4, p. 1, ago. 1921.

BARboSA, A. A Campanha e a educação. O Baptista Mineiro, anno I, n. 1, p. 3, jan. 1920.

COCKELL, H.E. A razão de ser. O Baptista Mineiro, anno I, n. 1, p. 1, jan. 1920.

COCKELL, H.E. Noticias da seara. O Baptista Mineiro, anno I, n. 4, p. 4, abr. 1920.

MADDOX, O.P. A grande campanha baptista. O Baptista Mineiro, anno I, n. 1, p. 2, jan. 1921.

O que é uma Egreja Baptista. O Baptista Mineiro, anno I, n. 5, p. 2, maio 1920.

Relatório do Collegio Baptista Americano Mineiro á Convenção Baptista de Minas Gerais em 1921. O Baptista Mineiro, anno II, n. 9, p. 3, set. 1921.

SHEPARD, J.W. Meditações sobre educação. O Baptista Mineiro, anno IX, n. 11 e 12, p. 1, nov./dez. 1928. 


\section{Livros e artigos}

CERTEAU, Michel de. A invenção do cotidiano: as artes de fazer. Petrópolis: Vozes, 1998.

CHARTIER, Roger. A história cultural: entre práticas e representações. Rio de Janeiro: Bertrand Brasil, 1990.

MESQUITA, Antônio Neves de. História dos Batistas do Brasil: 1907 até 1935. Rio de Janeiro: Casa Publicadora Batista, 1940.

PASSOS, Mauro. Entre a fé e a lei: o pensamento educacional católico no período republicano (1889 - 1930). LOPES, A.A.B.M.; GONÇALVES, I.A.; FARIA FILHO, L.M.; XAVIER, M.C. História da educação em Minas. Belo Horizonte: FCH/FUMEC, 2002. p. 183-196.

PEIXOTO, Ana Maria Casasanta. A luta dos católicos pela escola - Minas Gerais, anos 30. Educação em Revista, n. 17, jun. 1993. p. 56-63.

\section{Tese de doutoramento}

SOUZA, Rita de Cássia de. "Não premiarás, não castigarás, não ralharás...": dispositivos disciplinares em Grupos Escolares de Belo Horizonte (1925 - 1955). Tese de Doutoramento. São Paulo: Universidade de São Paulo, Faculdade de Educação, 2006.

Recebido em: 23/12/11

Aprovado em: 24/04/12 